\title{
Trilhas Interpretativas no Brasil: Uma Proposta Para o Ensino Básico
}

\section{INTERPRETIVE TRAILS IN BRAZIL: A PROPOSAL FOR BASIC EDUCATION}

\author{
Alexandre de Gusmão Pedrini ${ }^{1}$ \\ ${ }^{1}$.Doutor, Universidade do Estado do Rio de Janeiro (Brasil), Departamento de Biologia Vegetal, \\ Laboratório de Ficologia e Educação Ambiental, Rio de Janeiro, RJ, Brasil, pedrini @ globo.com/ \\ https://orcid.org/0000-0002-0406-0893.
}

\section{Recebido em 10/02/2019. Publicado em Agosto/2019}

Palavras-chave: Ensino de Biologia. Ensino de Ciências. Aula Extraclasse. Educação Ambiental. Paulo Freire
Keywords: Biology Teaching. Sciences Teaching. Out-ofclassroom Lesson. Environmental Education. Paulo Freire.
RESUMO: O ensino de Biologia ou de Ciências é passível de ser por aula extraclasse através de preleções em trilhas interpretativas (TIs). Se desconhece sua efetividade pedagógica. Os objetivos do trabalho são: a) propor um modelo de classificação para avaliar a efetividade das preleções; b) analisar preleções selecionadas por essa tipologia de análise; c) propor orientações para a formulação de preleções com base crítica-freirianas, abordando uma problemática socioambiental. Foram selecionados, ao acaso, no período de setembro a dezembro de 2017, vinte trabalhos, versando sobre atividades de ensino em TIs. A tipologia de avaliação da preleção proposta possui quatro níveis de efetividade: a) Efetividade Plena (EPe); b) Efetiva (E); c) Efetividade Parcial (EPa) d) Inefetiva (I). A quase totalidade das preleções $(90 \%)$ abordou questões socioambientais, mas a quase inexistência de problematização nelas foi marcante $(6 \%)$. As preleções EPe alcançaram $15 \%$ e as efetivas $25 \%$. A maioria das preleções (60\%) foram inadequadas (40\% de EPa somadas às $20 \%$ das inefetivas). As preleções foram biologizantes abordando a flora $(100 \%)$ e fracamente humanistas com a cultura local $(45 \%)$ e a ocupação histórica do território (55\%). A maioria das preleções ocorreu em TIs nos estados de São Paulo (30\%) e Rio de Janeiro (15\%). A extensão das TIs oscilou de 0,35-2,9 km com 3-14 pontos interpretativos. O público das preleções foi composto por alunos do ensino fundamental $(45 \%)$ e do ensino médio (25\%), portanto de maioria do ensino básico $(70 \%)$. As TIs foram $10 \%$ submarinas, sendo uma delas, parcialmente terrestre como o restante. São propostos 5 modelos de orientações para aulas extraclasses a serem ministrados em 9 pontos interpretativos ao longo de em uma trilha, quando uma questão socioambiental será problematizada, sob a perspectiva crítica-freiriana.

ABSTRACT: Extracurricular lessons in interpretive trails (ITs) bear potential for biology or science teaching. Their pedagogical effectiveness, however, remains unknown. This paper aims at filling that gap by: a) proposing a classification model for lecture effectiveness evaluation; b) using such classification to analyze previously selected lectures; c) proposing guidelines for the design of lectures about socioenvironmental issues from a critical Freirean perspective. For those purposes, we randomly selected a random sample of 20 works about extracurricular IT activities published from September to December 2017. Our typology for lecture evaluation consists of four effectiveness levels: a) Fully Effective (FE); b) Effective (E); c) Partially Effective (PE); Ineffective (I). Nearly all (90\%) lectures approached socioenvironmental issues, but hardly ever $(6 \%)$ were issues problematized. FE reached $15 \%$, while E amounted to $25 \%$. PE (40\%) and I (20\%), mostly inadequate, accounted together for the remaining $60 \%$. Lectures demonstrated a biologizing character by approaching flora $(100 \%)$, and were barely humanistic in dealing with 
Ensino, Saúde e Ambiente - V12 (2), pp. 230-259, Ago. 2019

local culture (45\%) and territorial settlement history (55\%). Most took place in the states of São Paulo (30\%) and Rio de Janeiro (15\%). Their length varied from 0.35 to $2.9 \mathrm{~km}$, with 3 to 14 interpretive spots. The lectures' participants comprised basic education students (45\%), general audiences (30\%) and high school students (25\%). Submarine ITs - one of which was partially terrestrial - were $10 \%$ of the sample, whereas the other $90 \%$ were totally terrestrial. We propose 5 lecture guideline models with 9 interpretive spots based on a critical Freirean framework.

\section{INTRODUÇÃO}

As aulas de Biologia ou de Ciências podem ser ministradas como aulas extraclasses. As aulas extraclasse recebem diferentes denominações por serem, via de regra, realizadas fora da escola. Os termos mais comuns são: a) aula de campo (SENICIATO E CAVASSAN, 2008); b) estudos do meio abrangendo excursões, visitas e entrevistas realizadas metodicamente fora da escola (MENDONÇA E NEIMAN, 2003). São aulas essencialmente lúdicas que se manifestam de múltiplas formas.

A aula extraclasse pode ser desenvolvida, por exemplo, em áreas naturais especialmente nas áreas protegidas como as unidades de conservação da natureza (UCs), jardins botânicos e zoológicos tanto públicos como privados que existem na maioria das grandes cidades brasileiras. Essas áreas, via de regra, senão estão localizadas dentro das cidades ou suas periferias podem ser alcançadas por meio de ônibus ou veículos escolares. Nelas espera-se haverá policiamento e, com proteção física para os alunos, se poderá abordar grande parte dos conteúdos socioambientais relativos a todas as três séries do ensino médio e as do segundo segmento do fundamental (LIMA et al., 2003; VASCONCELOS, 2006; ALVES, 2013; PIMENTEL et al. 2017, 2019).

Acompanhando e lendo os periódicos e os anais de eventos nacionais importantes em que os docentes de Biologia e Ciências publicam seus trabalhos nos últimos dez anos se percebe um aumento da adoção de aulas extraclasse em trilhas interpretativas. Cabe então revermos conceitos e tipologias.

\section{1 - TRILHAS INTERPRETATIVAS}

As trilhas interpretativas (TIs) ou com esse potencial são comuns de se encontrar nas UCs. Vasconcelos (2006) apresenta importante obra bibliográfica de interpretação e educação ambientais por trilha interpretativa (TI) em UCs. Nessa obra, é possível encontrar detalhamentos importantes sobre TI e como se planejar, formular e ministrar as aulas. É necessário não se minimizar a atividade nas TIs para que a aula não se transforme em aulapasseio. Não é suficiente dar uma lida na aula e combinar com os alunos na trilha. 
Ensino, Saúde e Ambiente - V12 (2), pp. 230-259, Ago. 2019

Para planejar uma aula adequada numa TI é interessante conhecer sua conceituação. Andrade e Rocha (2008) definem-na como um percurso de curta extensão em uma área natural que consiga promover um contato mais íntimo entre o Homem e a natureza. Deve ser um instrumento pedagógico que possibilite conhecer por onde se passe o seu ambiente como a flora, fauna, solo/rochas, história, geografia, processos biológicos, relações ecológicas e sua proteção, bem como o desenvolvimento de atitudes e valores nos indivíduos. Guimarães (2010) apresenta uma conceituação mais abrangente de TI como trajeto de curta distância (500-1.000 metros) em que se otimiza a compreensão das características naturais ou construídas e culturais da paisagem com o fim ludo-pedagógico direcionado à educação ambiental, funcionando como fator de integração ou reintegração de adaptação ou valoração de tomada de consciência.

Ao se levar alunos para uma aula extraclasse em uma TI, se consegue alguns benefícios em relação a uma área natural ampla como: a) controle mais fácil de cada um dos alunos; b) aglutinação e condução dos alunos em uma só direção; c) formação de grupos em número restrito, facilitando o controle de disciplina. Além disso, didaticamente é mais adequado, pois todos ficam concentrados no mesmo local onde é formulada a aula, ou seja, na TI (adaptado de ROCHA et al., 2017a). A utilização da TI pode variar desde o simples caminhar recreativo como para uma aula extraclasse. Em apoio às preleções, há recursos interpretativos complementares fixos como totens, fitas, placas e painéis e marcações interpretativas em pedras (ANDRADE E ROCHA, 2008). Há também material portátil como pôsteres e celulares com aplicativos.

Outro aspecto além da aula em si é a sua utilização frequente e seus efeitos físicos na trilha. O uso intermitente dos seres humanos e animais e as intempéries do tempo podem provocar impactação negativa nas trilhas e causar incidentes e acidentes graves aos seres que por ela transitam (LECHNER, 2006; VASCONCELOS, 2006). Por ser um percurso destinado a interpretação (sócio) ambiental (IA) pelas preleções, é necessário se conhecer alguns de seus conceitos basilares.

\section{II - A AUla EXTRAClasse Ministrada Pela PRELEÇÃo ATravéS DA INTERPRETAÇÃO (SÓCIO) AMBIENTAL}

No Brasil, os conceitos de IA mais adotados são derivados do filósofo norteamericano Freeman Tilden. Tilden (1977) foi o primeiro cientista a conceituar didaticamente interpretação (socio)ambiental (IA) afirmando que seu objetivo é revelar significados, fenômenos e fatos da natureza por meio de experiências práticas. Para Tilden (1977) a IA é contextual e precisa ser também: a) mobilizadora; b) de acordo com o perfil do participante; 
c) incentivar o participante a se envolver nas questões socioambientais identificadas no percurso da TI ou abordada pelo condutor; d) deve abordar um tema específico escolhido pelo condutor; e) prazerosa e divertida; f) organizada com as ideias encadeadas logicamente para fácil compreensão evitando a dispersão do participante. É notável que Tilden (1977) tenha incluído como pressuposto da IA o envolvimento do participante na problemática socioambiental da região geográfica da TI.

O produto da aula extraclasse é a formulação de uma preleção oral apoiada ou não com materiais didáticos fixos ou portáteis. A preleção precisa conter o conteúdo programático da ementa que cabe ao docente de biologia ou outra disciplina ministrar naquele semestre devidamente problematizado sobre uma questão socioambiental. O docente demanda, pelo menos, aos alunos (VASCONCELOS, 2006): a) concentração à aula; b) atenção à preleção; c) priorização do olhar a direção solicitada; d) produção de silêncio; e) conversa em voz bem baixa; f) compactação menor possível do solo ao caminhar; g) movimentação suave para não assustar os animais; h) documentação fotográfica sem flash para não adoecer os animais; i) evitar confraternização desautorizada (VASCONCELOS, 2006).

A utilização de aulas extraclasses em TIs pode parecer uma estratégia pouco utilizada no ensino de Biologia e Ciências no ensino básico. Entretanto, Alves (2013) ao fazer breve inventário aos termos Trilha Interpretativa na Internet surgiram 369 referências de trabalhos a respeito (em 2009), 420 referências (em 2010) e 398 referências (em 2011). Tais resultados mostram a pujança da adoção de aula extraclasse através das TIs como estratégia metodológica e mostram a necessidade de trabalhos de revisão, sob diferentes óticas. Em função desse grande número de trabalhos, os educadores vêm se preocupando em realizar avaliações críticas e reflexões sobre sua qualidade. Santos e Silva (2015) e Passeri (2016) investigaram trabalhos publicados nesse tema e verificaram que a maioria dos trabalhos analisados não conseguiram alcançar na prática a problematização crítica a que se propunham na sua narrativa. As preleções eram conservadoras e politicamente ingênuas. Além disso, esse tipo de aula demanda avaliações permanentes. Outra dificuldade verificada foi a falta de uma metodologia de avaliação com critérios claros que permitissem classificar os trabalhos em níveis de efetividade.

Desse modo, os objetivos principais do presente trabalho dirigido a docentes de biologia e de ciências que ministram aulas extraclasse em TIs são: a) propor um modelo de classificação de preleções pedagógicas de aulas extraclasses; b) apresentar uma tipologia avaliadora de efetividade da preleção; c) analisar um conjunto de aulas extraclasses descritas (ou atividades de ensino) em TIs em 20 trabalhos publicados no Brasil; d) propor orientações 
Ensino, Saúde e Ambiente - V12 (2), pp. 230-259, Ago. 2019

básicas de como planejar e realizar 5 modelos de aulas para serem adotadas em TIs. Essas orientações priorizam a perspectiva crítica-freiriana de ensino e problematizam uma questão socioambiental contemporânea.

\section{METODOLOGIA}

Esse artigo não aborda trilhas adaptadas, pois elas demandam competências específicas. São recomendados como ponto de partida os trabalhos de Maciel et al (2010) e Braga et al. (2015).

\subsection{OBTENÇÃO DOS TRABALHOS E CONCEITUAÇÃO}

Durante o período de setembro a dezembro de 2017 foi feito levantamento bibliográfico em um buscador na Internet (Google) através das palavras-chave: trilha, trilha interpretativa, trilha ecológica, trilha pedagógica, trilha educativa, trilha na natureza, trilha em sala de aula, aula de campo, aulas extraclasse, preleção/aula em trilha interpretativa, trilhas interpretativas ambientais, análise da eficácia de aulas/preleções nas TIs e análise de efetividade de aulas/preleções nas trilhas interpretativas. Os tipos de trabalhos aceitos para análise foram artigo de periódico, trabalho completo de eventos científicos, tese de doutorado, dissertação de mestrado ou trabalho de conclusão de curso de especialização ou graduação. Esse critério se deu por possibilitar a que o(s) autor(es) dos trabalhos tivesse(m) ampla oportunidade de detalhar sua metodologia e resultados, pois resumos simples ou estendidos não permitiriam o detalhamento necessário. O período selecionado das publicações foi de 2003-2017. Foi considerado nesse artigo como aula extraclasse o conjunto formado pela preleção somado ao material de apoio levado pelo docente (ou monitor/facilitador capacitado) ou pré-existente na TI (ou atividade didática similar com o mesmo caráter).

\subsection{CRITÉRIOS DE FORMULAÇÃO DOS QUADROS E DO QUE ELES CONTÊM E EXPRESSAM}

O Quadro 1 apresenta os 20 trabalhos selecionados ao acaso que tinham como objetivo ministrar aulas extraclasse ou atividade didática similar com o mesmo caráter em TIs. Caracteriza o trabalho quanto ao(s) seu(s) autor(es), estado e cidade/local onde a trilha se localiza, o público a que se destina, o bioma/ecossistema abordado, tempo da preleção/atividade, distância percorrida e o número de pontos interpretativos. Inclui os trabalhos cujos temas tratassem de áreas protegidas, educação ambiental, trilhas, geobiodiversidade, diversidade humana, ecologia e temas correlatos, pois neles era de se esperar que fossem problematizados a ação humana e seu risco, no mínimo potencial a vida 
Ensino, Saúde e Ambiente - V12 (2), pp. 230-259, Ago. 2019

planetária. Trabalhos que no título expressavam tratar apenas a flora, fauna ou geotrilhas, por exemplo também não foram selecionados.

O Quadro 2 apresenta um modelo de classificação que permite avaliação das preleções pedagógicas ministradas em trilhas interpretativas e cria uma tipologia de avaliação de efetividade das preleções. A efetividade se classifica em 4 níveis: a) Efetividade Plena (EPe); b) Efetiva (E); c) Efetividade Parcial (EPa) d) Inefetiva (I). Esses níveis são obtidos pela análise de três indicadores gerais e seus respectivos parâmetros: 1) Apresentação da Geobiodiversidade (local): flora; fauna; solo; 2) Apresentação da Diversidade Humana (local): população (populações tradicionais, indígenas, quilombolas, caiçaras, pescadores, outros); cultura (artesanato, rendas, etc); Ocupação histórica do território (como ocorreu a ocupação do território terrestre ou aquático); 3) Apresentação da Questão Socioambiental: Menção; Problematização (Problematização crítica-freiriana existente no trajeto, arredores ou cidade onde a trilha esteja situada). Critérios de pontuação para classificação da efetividade da preleção: a) ocorrência simples: 1.0 pontos; b: ocorrência problematizada: 2,0 pontos. A Escala de Pontos de efetividade se mede da seguinte forma: Efetividade Plena: (9 p); Efetiva: (7-8 p); Efetividade Parcial (4-6 p.); Inefetiva: (1-3 p).

O Quadro 3 visa dar as bases metodológicas ao docente inexperiente em aula extraclasse do ensino básico interessado em formular preleções em uma TI e desenvolver material elementar de apoio e instrumento simples de avaliação de desempenho dos alunos. Para facilitar metodologicamente ao docente inexperiente ou iniciante em aula extraclasse do ensino básico, interessado em formular preleções em TI é apresentado esse roteiro-síntese orientador que é o Quadro 3. O Quadro 3 propõe também um modelo de orientações mínimas para formulação de preleção, tendo como referência ideal o modelo de Efetividade Plena do Quadro 2.

Dos 5 padrões de orientações que são sinteticamente apresentados, 3 são contextos mais verificados pelos docentes no levantamento bibliográfico (áreas protegidas-unidades de conservação, áreas naturais e espaços dentro da escola). Além disso, foram agregados dois contextos pouco utilizados (sala de aula extra e praça pública) pedagogicamente, mas que podem ser úteis aos docentes. Para a proposição dos cinco modelos de orientações para formulação das preleções foram consultados os trabalhos dos autores a seguir, de acordo com os seguintes temas: a) sentidos: Matarezi (2000/2001), Araujo e Farias (2003), Dias (2010) e Maciel et al. (2010); b) trilha portátil: Matarezi e Bonilha (2000); c) praça pública: Almeida et al. (2004), Saito (2012), Pedrini et al. (2015) e Cunha (2016); d) problematização críticafreiriana: Freire (1987, 2011, 2013), Saito (1999), Chapani e Daiben (2003), Loureiro (2006), 
Ensino, Saúde e Ambiente - V12 (2), pp. 230-259, Ago. 2019

Tozoni-Reis (2006), Figueiredo (2007), Quintas (2009), Torres e Delizoicov (2009), Loureiro e Torres, (2014), Araujo (2015), Müller e Torres (2015) e Torres (2018); e) trilhas e áreas naturais: Andrade e Rocha (1997), Lechner (2006), Santos (2007), Ikemoto (2008), Guimarães (2010), Alves (2013) e Eisenlohr et al. (2013); f) biodiversidade e unidades de conservação da natureza: Telles (2002), Mendonça e Neiman (2003), Meirelles et al. (2013) e Pimentel et al. (2017); g) TIs marinhas: Berchez et al. (2007), Pedrini et al. (2019) e Zau (2018); h) avaliação: Tabanez et al. (1997), Dias e Zanin (2004) e Curado e Angelini (2006); i) metodologia em geral: Mion e Saito (2001), Tozoni-Reis (2006, 2007), El-Deir (2013), Pedrini e Saito (2014) e Barbosa et al. (2019).

\section{RESULTADOS e DISCUSSÃO}

\subsection{A AULA NUMA TRILHA INTERPRETATIVA}

A aula extraclasse numa TI está sendo centrada para docentes de Biologia e Ciências, mas ela pode e deve ser estendida para as outras disciplinas da escola, abordando e problematizando a questão socioambiental. Foi verificada abordagem da questão socioambiental por docentes de Biologia, Ciências e Geografia, baseando-se no conceito amplo de que meio ambiente abrange a totalidade em que se vive (MEC, 1998).

O Quadro 1 apresenta os 20 trabalhos examinados que pertencem a 10 estados brasileiros. A maioria (30\%) é do estado de São Paulo seguida pelo estado do Rio de Janeiro (15\%) e depois pelos estados do Rio Grande do Sul (10\%), Rio Grande do Norte (10\%) e Santa Catarina (10\%). Seguem os estados de Alagoas, Goiás, Minas Gerais, Mato Grosso do Sul e Paraíba, cada um com 5\%. É uma amostra representativa, pois só não estão presentes trabalhos da região da Floresta Amazônica onde certamente ainda não devem ter muitas TIs pedagógicas, sendo adotadas para a EA. As cidades onde as trilhas ocorrem são na maioria do interior, excetuando-se 4 delas (20\%) que são de Niterói, Rio de Janeiro e Natal. Mesmo assim as TIs são de UCs. O público a que se destina as preleções dos trabalhos são na maioria alunos do ensino fundamental (45\%), seguido do Grande Público (30\%) e ensino médio (25\%). A maioria absoluta de $70 \%$ é do ensino básico.

O Quadro 1 ainda mostra que o bioma/ecossistema dos trabalhos analisados $10 \%$ são de trilhas submarinas, sendo uma delas, parcialmente terrestre no Parque Estadual da Ilha Grande (PEIG-RJ). A trilha marinha (TM) integral situa-se no Parque Estadual da Ilha Anchieta (PEIA-SP). Ambas ocorrem na área de amortecimento dos dois parques terrestres (BERCHEZ et al, 2007). Pedrini (2013b) identificou, pela primeira vez, que das doze TMs do Brasil somente cerca de $30 \%$ são pedagógicas. Ainda se pode verificar que os 
Ensino, Saúde e Ambiente - V12 (2), pp. 230-259, Ago. 2019

biomas/ecossistemas terrestres abordados são na maioria absoluta (80\%) de vegetação primária. Desses, cerca de 55\% é na Mata Atlântica (MA), seguida do Cerrado (25\%) e depois da Caatinga (15\%). A MA percorre a costa brasileira do sul ao nordeste brasileiro, fazendo fronteira com vários outros biomas, justificando esse predomínio.

Quadro 1 - Características contextuais da trilha interpretativa, do público envolvido e da preleção realizada.

\begin{tabular}{|c|c|c|c|c|c|c|}
\hline Autor & Estado & $\begin{array}{l}\text { Cidadel } \\
\text { Local }\end{array}$ & Público & $\begin{array}{l}\text { Bioma/ } \\
\text { Ecossistema abordado }\end{array}$ & $\begin{array}{ll}\text { Tempo na } \\
\text { Preleção }\end{array}$ & $\begin{array}{l}\text { Distância } \\
\text { percorrida/N } \\
\text { pontos } \\
\text { interpretativos }\end{array}$ \\
\hline 1.Alves (2013) & MS & Dourados & Alunos EF & Msta de vegetaçăo secundária & NI & $0,40 \mathrm{~km} / \mathrm{NI}$ \\
\hline 2.Angelini ot al. (2011) & GO & Anápolis & Alunos do EM & Cerrado & $1 \mathrm{~h}$ & NV/NI \\
\hline 3. Araujo (2016) & AL & $\begin{array}{l}\text { Palmeira } \\
\text { dos Indios }\end{array}$ & Alunos do EM & Cantinga/Mata Atlantica & NI & NV/4 pi \\
\hline 4.Barcellos et al. (2013) & $\mathrm{RJ}$ & Niterofi & Público identificado & Mata Atlintica & NI & $2,6 \mathrm{~km} / 6 \mathrm{pi}$ \\
\hline 5.Berchez et al. (2007) & SP & $\begin{array}{l}\text { Ubatuba/lih } \\
\text { a Anchieta }\end{array}$ & Público em geral & Submarino & $1 \mathrm{~h}$ & $0,35 \mathrm{~km} / 8 \mathrm{pi}$ \\
\hline $\begin{array}{l}\text { 6.Cazoto e Tozoni-Reis } \\
\text { (2008) }\end{array}$ & SP & Botucatu & Alunos do EF & Cerrado & NI & NUNI \\
\hline $7 . \operatorname{Cec} c 00(2008)$ & SP & Assis & Alunos do EM & Cerrado & NI & NV/NI \\
\hline 8.Copatti et al. (2011) & RS & Cruz Alta & Alunos do EM & Mata Atlântica (MA) & $3 \mathrm{~h}$ & $2,0 \mathrm{~km} / 9 \mathrm{pi}$ \\
\hline 9.Costa et al. (2014) & $\mathrm{RN}$ & Natal & Alunos do EF & Vegetação Secundária (VS) & NI & NV/6 pi \\
\hline 10.Dí Tulio (2005) & SP & $\begin{array}{l}\text { São José do } \\
\text { Rio Pardo }\end{array}$ & Alunos do EF & Mata Ciliar & NI & $2,90 \mathrm{~km} / 11 \mathrm{pi}$ \\
\hline 11.Fontana et al (2015) & SC & Joaçaba & Público em geral & Floresta Ombrofila/MA & Ih 30 & $1,216 \mathrm{~km} / 14 \mathrm{pi}$ \\
\hline 12.Guerra (2005) & MG & $\begin{array}{l}\text { Vespasiano } \\
\text { Lagoa } \\
\text { Santa }\end{array}$ & Alunos do EF & Mata Atlantica, /Cerrado & $40 \min$ & $1,0 \mathrm{~km} / 5 \mathrm{pi}$ \\
\hline 13.Lima $e$ al. (2003) & SP & $\begin{array}{l}\text { Nazaré } \\
\text { Paulista }\end{array}$ & Alunos do EF & VS/Mata Atlântica & NI & $1,50 \mathrm{~km} / 7 \mathrm{pi}$ \\
\hline 14.Lima $\alpha$ al. (2015) & $\mathrm{Pb}$ & Cuite & Alunos do EM & Caatinga & NI & NU/NI \\
\hline 15.Martins et al. (2007) & RS & Uruguaiana & Público em geral & VS & Variável & $0,852 \mathrm{~km} / 6 \mathrm{pi}$ \\
\hline 16. Meireles et al. (2013) & RJ & $\begin{array}{l}\text { Angra dos } \\
\text { Reis }\end{array}$ & Público em geral & Marinho/Mata Attântica & NI & $2,6 \mathrm{~km} / 11 \mathrm{pi}$ \\
\hline 17.Moritzet al (2014) & $\mathrm{RN}$ & Natal & Adolescentes e adultos & Dunas & Th meia & $2,40 \mathrm{~km} / \mathrm{NI}$ \\
\hline 18.Rocha ot al (2017a) & RJ & RJ & Alunos do EF e EM & Mata Atlantica & NI & NI/8 pi \\
\hline $\begin{array}{l}\text { 19. Santos e Almeida } \\
\text { (2011) }\end{array}$ & SP & Lins & Alunos do EF & Vegetaçào Secundária & $40 \min$ & NVINI \\
\hline $\begin{array}{l}\text { 20.Souza e Cremer } \\
\text { (2016) }\end{array}$ & SC & Joinville & Alunos do EF & Mata Atlantica & $40 \min$ & $0,50 \mathrm{~km} / 3 \mathrm{pi}$ \\
\hline
\end{tabular}


Ensino, Saúde e Ambiente - V12 (2), pp. 230-259, Ago. 2019

A maioria dos autores negligenciaram a informação do tempo de duração das suas preleções. Observa-se uma variação de 40 min-3 horas, com maior frequência no primeiro tempo (cerca de 40\%) e menor frequência (cerca de 15\%) no segundo. A preleção que durou $3 \mathrm{~h}$ foi na trilha de menores comprimento e número de pontos interpretativos (9). $\mathrm{O}$ comprimento das trilhas oscilou de 0,35-2,9 km. O número de pontos interpretativos oscilou de 3-14 pontos, predominando em 6 (25\%), seguido de 8 (17\%) e 11 (17\%). Então, parece que as preleções não são demoradas, atingindo, no máximo, $1 \mathrm{~h}$ em menos de $3 \mathrm{~km}$ com até 14 pontos interpretativos.

\subsection{ANÁLISE DAS PRELEÇÕES NOS TRABALHOS}

O Quadro 2 apresenta um modelo de classificação das preleções pedagógicas das aulas extraclasses ministrados nas TIs. Cria, também, uma tipologia de avaliação de efetividade das preleções, propondo unidades de comparação o que permite uma análise comparativa entre os resultados dos trabalhos de aulas extraclasse em TIs. Apresenta uma análise detalhada das preleções das TIs dos 20 trabalhos obtidos pela internet, segundo os critérios elencados na metodologia. A análise tenciona, segundo os indicadores selecionados reunir, o mínimo de características que uma preleção deva compreender em se tratando de uma abordagem de questão socioambiental. Essas características associadas a menção do conteúdo temático a ser abordado da aula e a sua problematização crítica-freiriana pode entender-se como sendo o mínimo a ser comunicado na preleção de uma aula.

O Quadro 2 mostra apenas 3 trabalhos (15\%) que apresentaram preleções classificadas com Efetividade Plena. São orientados pela EA crítica que possui os mesmos pressupostos básicos da EA crítica-freiriana (DI-TULIO, 2005; BARCELLOS et al., 2013; MEIRELLES et al. 2013). O Quadro 2 mostra também que 90\% das preleções abordaram a questão socioambiental e apenas $30 \%$ delas com problematizações nominalmente crítica-freirianas. Esse resultado é preocupante, pois as preleções não problematizam as reais causas históricas da degradação socioambiental do planeta. É fundamental que doravante os docentes nas aulas extraclasses nas TIs se aperfeiçoem nas teorias problematizadoras como a crítica-freiriana. 
Ensino, Saúde e Ambiente - V12 (2), pp. 230-259, Ago. 2019

Por outro lado, Cazoto e Tozoni-Reis (2008), Ceccon (2008), Alves (2013) e Rocha et al. (2017a) apresentaram problematização crítica-freiriana. Contudo, não descreveram os parâmetros necessários no texto dos seus trabalhos para sua classificação como Efetivamente Plena. Isso pode ter ocorrido porque o presente trabalho permitiu apenas uma análise bibliográfica e não empírica.

O Quadro 2 ainda evidencia uma baixa percepção humanista nas preleções com nível inexpressivo para cultura (45\%) por onde a trilha passa e igualmente baixo sobre a percepção da ocupação histórica do território (55\%). Esses resultados contrastam com a importância conferida à flora $(100 \%)$ e fauna $(85 \%)$ local da TI. São preleções biologizantes. Fica evidenciado que o perfil dos docentes analisados seja essencialmente de professores de Biologia e de Ciências (conteúdo de biologia). É importante lembrar que as preleções tiveram Efetividade Parcial (40\%) e inefetividade (20\%), ou seja, $60 \%$ delas não apresentaram efetividade. A tipologia proposta conseguiu evidenciar que essa ausência da diversidade humanista nos indicadores selecionados prejudica sua classificação efetiva como uma preleção desejada para ser ministrada numa TI. Concluindo, é patente essa visão majoritária dirigida para a conservação da natureza, apresentando o Homem apenas como degradador e não como parte da solução (BERCHEZ et al. 2007; ANGELINI et al. 2011).

Quadro 2: Análise detalhada das preleções das trilhas interpretativas dos trabalhos obtidos quanto a sua efetividade pedagógica. Legenda: Apresentação da Geobiodiversidade (AG=3): Fl: Flora; Fa. Fauna; G: Geologia; Apresentação da Diversidade Humana (ADH=3): Po: População; C: Cultura: H: História; Apresentação da Questão Socioambiental (AQS=3): M: Menção; P: Problematização (=problematização crítica-freiriana); Tipologia da Preleção: EPe: Efetividade Plena; E: Efetiva; EPa: Efetividade Parcial; I: Inefetiva. Critérios de pontuação, sendo cada ocorrência 1.0 (p: ponto) exceto a problematização que vale 2,0; a pontuação em $\mathrm{P}$ pontua também em $\mathrm{M}$. 
Ensino, Saúde e Ambiente - V12 (2), pp. 230-259, Ago. 2019

\begin{tabular}{|c|c|c|c|c|c|c|c|c|c|c|c|c|c|}
\hline \multirow[t]{2}{*}{$\mathrm{N}^{0}$} & \multirow[t]{2}{*}{ Autores } & \multicolumn{3}{|c|}{$\begin{array}{l}\text { Apresentação } \\
\text { da } \\
\text { Geobiodiversid } \\
\text { ade local (1-3) }\end{array}$} & \multicolumn{3}{|c|}{$\begin{array}{c}\text { Apresentação } \\
\text { da } \\
\text { Diversidade } \\
\text { Humana } \\
\text { local (1-3) }\end{array}$} & \multicolumn{2}{|c|}{$\begin{array}{c}\text { Apresentação } \\
\text { da Questão } \\
\text { Socioambient } \\
\text { al Abordada } \\
\text { (1-3) }\end{array}$} & \multicolumn{4}{|c|}{$\begin{array}{c}\text { Tipologia da } \\
\text { Preleção }\end{array}$} \\
\hline & & $\begin{array}{c}\mathrm{Fl} \\
1\end{array}$ & $\begin{array}{c}\mathrm{Fa} \\
1\end{array}$ & $\begin{array}{c}\mathrm{G} \\
1\end{array}$ & $\begin{array}{c}\text { Po } \\
1\end{array}$ & $\begin{array}{l}\mathrm{C} \\
1\end{array}$ & $\begin{array}{l}\mathrm{H} \\
1\end{array}$ & $\begin{array}{c}\mathrm{M} \\
1\end{array}$ & $\begin{array}{l}\mathrm{P} \\
2\end{array}$ & $\begin{array}{l}\text { EP } \\
e \\
\text { (9) }\end{array}$ & \begin{tabular}{|l}
$E$ \\
$(7-$ \\
$8)$
\end{tabular} & $\begin{array}{l}\mathrm{EPa} \\
(4-6)\end{array}$ & $\begin{array}{l}\text { I } \\
(1- \\
3)\end{array}$ \\
\hline 1 & $\begin{array}{l}\text { Alves } \\
\text { (2013) }\end{array}$ & 1 & 1 & & 1 & 1 & & 1 & 2 & & 7 & & \\
\hline 2 & $\begin{array}{l}\text { Angelini } \\
\text { et al. } \\
(2011)\end{array}$ & 1 & 1 & 1 & 1 & & & 1 & & & & 5 & \\
\hline 3 & $\begin{array}{l}\text { Araujo } \\
\text { (2016) }\end{array}$ & 1 & & & 1 & 1 & 1 & 1 & & & & 5 & \\
\hline 4 & $\begin{array}{l}\text { Barcellos } \\
\text { et al. } \\
\text { (2013) }\end{array}$ & 1 & 1 & 1 & 1 & 1 & 1 & 1 & 2 & 9 & & & \\
\hline 5 & $\begin{array}{l}\text { Berchez } \\
\text { et al. } \\
(2007)\end{array}$ & 1 & 1 & 1 & & & & 1 & & & & 4 & \\
\hline 6 & $\begin{array}{l}\text { Cazoto e } \\
\text { Tozoni- } \\
\text { Reis } \\
(2008)\end{array}$ & 1 & & 1 & 1 & & 1 & 1 & 2 & & 7 & & \\
\hline 7 & $\begin{array}{l}\text { Ceccon } \\
(2008)\end{array}$ & 1 & 1 & 1 & 1 & 1 & 1 & 1 & & & 7 & & \\
\hline 8 & $\begin{array}{l}\text { Copatti et } \\
\text { al. (2011) }\end{array}$ & 1 & 1 & 1 & & & 1 & 1 & & & & 5 & \\
\hline 9 & $\begin{array}{l}\text { Costa et } \\
\text { al. (2014) }\end{array}$ & 1 & 1 & 1 & & & & & & & & & 3 \\
\hline
\end{tabular}

Quadro 2: Análise detalhada das preleções das trilhas interpretativas dos trabalhos obtidos quanto a sua efetividade pedagógica. Legenda: Apresentação da Geobiodiversidade (AG=3): 
Ensino, Saúde e Ambiente - V12 (2), pp. 230-259, Ago. 2019

Fl: Flora; Fa. Fauna; G: Geologia; Apresentação da Diversidade Humana (ADH=3): Po: População; C: Cultura: H: História; Apresentação da Questão Socioambiental (AQS=3): M: Menção; P: Problematização (=problematização crítica-freiriana); Tipologia da Preleção: EPe: Efetividade Plena; E: Efetiva; EPa: Efetividade Parcial; I: Inefetiva. Critérios de pontuação, sendo cada ocorrência 1.0 (p: ponto) exceto a problematização que vale 2,0; a pontuação em $P$ pontua também em M. (Continuação)

\begin{tabular}{|c|c|c|c|c|c|c|c|c|c|c|c|c|c|}
\hline 10 & $\begin{array}{l}\text { Di Tulio } \\
\text { (2005) }\end{array}$ & 1 & 1 & 1 & 1 & 1 & 1 & 1 & 2 & 9 & & & \\
\hline 11 & $\begin{array}{l}\text { Fontana et } \\
\text { al. (2012) }\end{array}$ & 1 & 1 & 1 & & & & 1 & & & & 4 & \\
\hline 12 & $\begin{array}{l}\text { Guerra } \\
(2005)\end{array}$ & 1 & 1 & 1 & & & & & & & & & 3 \\
\hline 13 & $\begin{array}{l}\text { Lima et } \\
\text { al. (2003) }\end{array}$ & 1 & 1 & & 1 & 1 & 1 & 1 & & & & 6 & \\
\hline 14 & $\begin{array}{l}\text { Lima et } \\
\text { al. (2015) }\end{array}$ & 1 & 1 & 1 & 1 & 1 & 1 & 1 & & & 7 & & \\
\hline 15 & $\begin{array}{l}\text { Martins et } \\
\text { al. (2007) }\end{array}$ & 1 & 1 & 1 & & & & 1 & & & & 4 & \\
\hline 16 & $\begin{array}{l}\text { Meireles et } \\
\text { al. (2013) }\end{array}$ & 1 & 1 & 1 & 1 & 1 & 1 & 1 & 2 & 9 & & & \\
\hline 17 & $\begin{array}{l}\text { Moritz et al. } \\
\text { (2014) }\end{array}$ & 1 & 1 & & & & & 1 & & & & & 3 \\
\hline 18 & $\begin{array}{l}\text { Rocha et } \\
\text { al. (2017a) }\end{array}$ & 1 & 1 & & 1 & 1 & 1 & 1 & 2 & & 8 & & \\
\hline 19 & $\begin{array}{l}\text { Santos e } \\
\text { Almeida } \\
\text { (2011) }\end{array}$ & 1 & & & & & 1 & 1 & & & & & 3 \\
\hline 20 & $\begin{array}{l}\text { Souza e } \\
\text { Cremer } \\
(2016)\end{array}$ & 1 & 1 & 1 & & & & 1 & & & & 4 & \\
\hline - & Total & 20 & 17 & 14 & 11 & 9 & 11 & 18 & 6 & 3 & 5 & 8 & 4 \\
\hline - & $\%$ & 100 & 85 & 70 & 55 & 45 & 55 & 90 & 30 & 15 & 25 & 40 & 20 \\
\hline
\end{tabular}

Conclui-se que, além de uma capacitação problematizadora (crítica-freiriana ou de outra perspectiva) é fundamental para que os docentes de Biologia e Ciências possam se dar 
Ensino, Saúde e Ambiente - V12 (2), pp. 230-259, Ago. 2019

conta de que o Homem é parte do meio e da solução da problemática socioambiental contemporânea. $\mathrm{O}$ docente precisa identificar e caracterizar a diversidade humana tal como a diversidade geobiológica do contexto da TI selecionada para sua aula, problematizando a questão socioambiental da sua região geográfica. Com essas informações ele então deve formular sua preleção para uma adequada aula extraclasse, abordando o tema meio ambiente como conteúdo programático de sua disciplina.

\subsection{PROPOSTA DE MODELOS DE ORIENTAÇÕES PARA FORMULAÇÃO DE}

\section{PRELEÇÕES}

\subsubsection{INTRODUÇÃO}

São propostos cinco modelos de orientações para formulação de preleções que poderão ser adotadas nas aulas extraclasses a serem aplicadas em TIs, com ou sem estratégias didáticas ou material de apoio. Antes de se conhecer os modelos orientadores para formulação das preleções é importante, para o planejamento adequado da aula extraclasse, se definir o tema da aula e qual material de apoio será usado.

\subsubsection{DEFINIÇÃO DO TEMA DA AULA}

Normalmente a definição do tema da aula é definida pelo docente, segundo a ementa ou lista do conteúdo programático que ele tem cumprir no bimestre. Caso se escolha usar “tema gerador" é necessário se adotar uma metodologia criteriosa e exclusiva desenvolvida por Paulo Freire (FREIRE, 1987; 2011; 2013). Freire é o educador brasileiro mais citado no mundo, mas para afirmar que foi adotada sua metodologia ou a “Abordagem Temática Freiriana" é necessário implicar todo o processo com as cinco etapas. O tema gerador é produzido como parte final de um processo centrado na problemática do contexto de vida dos alunos. Não se obtém apenas fazendo um questionário de improviso ou mapas mentais sem análise derivada de um referencial teórico problematizador. A metodologia freiriana foi formulada originalmente para alfabetizar camponeses oprimidos em ditaduras, evitando o programa imposto pelo governo. Posteriormente, professores de Ciências (DELIZOICOV, ANGOTTI e PERNAMBUCO, 2018) adaptaram para o ensino básico.

Alves (2013), Müller e Torres (2015) e Torres (2018) são docentes freirianos de Biologia e Ciências com experiência na "Abordagem Temática Freiriana" com excelentes trabalhos em escolas de ensino básico. Com base neles, é proposta uma aula extraclasse numa TI para docentes no ensino de biologia e ciências-conteúdo biologia que deseje produzir temas geradores, segundo a Abordagem temática Freiriana, seguindo as etapas seguintes: 1) 
Ensino, Saúde e Ambiente - V12 (2), pp. 230-259, Ago. 2019

Levantamento das condições/contradições em que vivem os alunos para serem superadas pelo conhecimento científico (identificação das situações-limite, segundo FREIRE, 1987); 2) Análise das situações e Codificação (Construção de categorias de análise); 3) Diálogos Descodificadores, ou seja, realização de diálogos problematizadores entre o docente e os alunos sobre as situações limites e aquelas levantadas na etapa 1, validando-as ou não (a partir deles se se obtêm os temas geradores); 4) Redução temática (nessa fase os temas geradores são reduzidos a conteúdos específicos que representem as contradições identificadas na etapa 1); 5) Aula na TI [Adoção da preleção sobre o(s) tema(s) gerador(es) selecionado(s)].

\subsubsection{MATERIAL DE APOIO DIDÁTICO}

Existem vários materiais para apoio didático em áreas protegidas e que podem ser úteis numa TI, como guias de bolso e livros de aula prática de campo. Entretanto, aqui no país, em geral, generalistas, pois há centenas de UCs e biomas diferentes. Em poucas áreas protegidas há guias didáticos de animais como aves, mamíferos ou répteis ou plantas como frutíferas para serem identificados sem auxílio de um professor de biologia ou ciências.

\subsubsection{LIVROS}

Há limitadas obras para aulas práticas no campo com aplicação específica para trilhas interpretativas no país. Em termos de identificação taxonômica de fauna, flora e solo apenas recentemente é que algumas editoras privadas arriscaram capital para publicar livros sobre nossa biodiversidade marinha (p. ex. Technical Books; PEDRINI, 2013b). Há livros que são guias de bolso, havendo confusão nessa terminologia.

\subsubsection{GUIAS}

Há limitadíssimos guias bem estruturados e cientificamente aprovados no país. Ghilardi-Lopes et al. (2012) formularam um guia para atividades em trilhas marinhas nos costões rochosos do sudeste brasileiro. Pedrini et al. (2018) formularam um guia fotográfico de macroalgas marinhas e estuarinas em PVC para uma praia do PEIG (RJ) que pode ter seu uso estendido às praias do sudeste brasileiro. Para ações de EA em trilhas terrestres Siqueira (2013) formulou um completo guia virtual para o Parque Nacional da Tijuca (PNT) na cidade do Rio de Janeiro. Santos et al. (2017) formularam interessante artigo sobre a avaliação de guias didáticos em biologia.

\subsubsection{PLACAS INTERPRETATIVAS}


Ensino, Saúde e Ambiente - V12 (2), pp. 230-259, Ago. 2019

As placas interpretativas estão dispostas lateralmente à trilha e podem conter informações úteis, auxiliando bastante à preleção do docente. Informações também podem ser alocadas nas cercas, rochas, troncos, fitas, totens, dentre outras opções (LECHNER, 2006; VASCONCELOS, 2006).

\subsubsection{APLICATIVOS DE CELULAR}

Já existem aplicativos educacionais para adoção tanto em sala de aula como em aulas de campo (STEINERT e HARDOIM, 2017; ROCHA et al. 2017b). Um recurso didático inovador para celulares em TIs é a realidade aumentada (vide ARAUJO, 2019).

Em suma, após essa brevíssima introdução serão apresentados minimamente os cinco modelos de orientações para formulação de preleções para adoção em TIs.

\subsubsection{MODELO DE ORIENTAÇÕES PARA PRELEÇÃO EM SALA DE AULA}

Mesmo em se tratando de aula extraclasse, esse modelo se ajusta para aplicação em outras salas de aula, adotando uma trilha portátil e no modelo de ensino não formal no espaço formal da escola. A criação de preleções de trilha em sala de aula já foi mencionada formalmente no modelo Trilha da Vida de Matarezi e Bonilha (2000) e Matarezi (2000/2001). Ela é a forma móvel do modelo fixo da Trilha da Vida. A diferença é que na trilha móvel tenta-se trazer o ambiente selecionado para a sala de aula, simulando-o. Incrementa-se a aparência da simulação, acrescentando-se vasos com plantas do ambiente pensado, areia local, incenso e aromas naturais, água, ventilador, etc. Solicita-se aos alunos para imaginarem mentalmente o ambiente.

Em salas de aula extras será mais difícil essa preleção com os nove Pontos Interpretativos (PIs), caso a sala seja muito pequena com os lados muito próximos. A TI que está sendo proposta é uma que deve ser delineada dentro da sala com desmobilização das carteiras de modo a que os pontos interpretativos possam ser, pelo menos, os quatro cantos da sala e no centro. Os outros PIs podem ser marcados no meio dos outros já definidos, totalizando 9 no total. Nesses pontos haverá as preleções pedagógicas previamente planejadas e escritas para cada um deles. Devem ser agregados aromas, sons e outros acessórios que ajudem a criar um ambiente similar ao ecossistema desejado. Os alunos devem mentalizar o ecossistema a ser visitado. Podem ser feitos pôsteres ou coladas fotografias em cartolinas e colocadas nos pontos interpretativos, etc. Já existem aplicativos educativos para celulares gratuitos formulados no Brasil para adoção em sala de aula (ROCHA et al. 2017b). A 
Ensino, Saúde e Ambiente - V12 (2), pp. 230-259, Ago. 2019

projeção de um filme sobre o ambiente a ser abordado também vai ajudar a criar um clima adequado aos ensinamentos.

\subsubsection{MODELO DE ORIENTAÇÕES PARA PRELEÇÃO NAS PARTES COMUNS DA ESCOLA}

Muitas escolas possuem salas de aulas impossíveis de se simular uma trilha porque têm alunos em excesso ou as carteiras são muito coladas entre elas. A solução pode ser uma TI nas suas proximidades imediatas, mas dentro da escola em seus espaços mais amplos como quadras, pátios ou áreas verdes. Há centenas de escolas no país em que há áreas gramadas ou com jardins e árvores, hortas ou pomares em que se pode criar uma TI (COSTA et al., 2014). Em muitas delas existem jardins didáticos. Nessas áreas é possível se planejar, construir, marcar e manter uma TI curta/média ou extensa com fins pedagógicos, podendo-se agregar totens, placas e fitas interpretativas.

\subsubsection{MODELO DE ORIENTAÇÕES PARA PRELEÇÃo EM PRAÇA PUBLICA}

As praças públicas são muito valorizadas no interior do país, pois ainda são locais bem seguros para passear mesmo à noite. Durante o dia, mesmo nas cidades grandes e metrópoles, pode-se pedir auxílio às guardas municipais e fazer atividades pedagógicas com segurança. Nelas, principalmente aos finais de semana, as pessoas praticam esportes, ginástica, vendem roupas e artesanato, andam de bicicleta, jogam cartas ou damas, fazem pic-nics, tocam instrumentos, encontram amigos, passeiam, dentre outras atividades saudáveis. Educadores vêm promovendo ações pedagógicas em metrópoles como a cidade do Rio de Janeiro com sucesso, mesmo convivendo com essas outras atividades (ALMEIDA et al., 2004; MACIEL et al., 2010; CUNHA, 2016).

\subsubsection{MODELO DE ORIENTAÇÕES PARA PRELEÇÃO EM ÁREA NATURAL}

A utilização de áreas naturais ou naturalizadas privadas ou públicas como quintais, sítios, fazendas, florestas e campus das universidades. Têm sido muito comuns para atividades de recreação, lazer e sensibilização (CORNELL, 2008). Têm sido usadas para preleções em TIs e para educação ambiental (LIMA et al., 2003; ALVES, 2013). Esse modelo é para preleções em áreas que não estejam dentro ou na zona de entorno imediato às UCs que se encaixam no próximo modelo.

\subsubsection{MODELO DE ORIENTAÇÕES PARA PRELEÇÃO EM UNIDADES DE CONSERVAÇÃO DA NATUREZA}


Ensino, Saúde e Ambiente - V12 (2), pp. 230-259, Ago. 2019

Esse modelo é o mais comum e existe inúmeros tipos de áreas protegidas como parques e jardins botânicos ou zoológicos. Há as unidades de conservação da natureza (UCs). Nas áreas protegidas as trilhas não podem ser modificadas, pois são patrimônio público. As preleções pedagógicas ocorrem nas TT (BARCELOS et al., 2013) ou de água doce (BARBOSA E PERINOTTO, 2016) ou ainda podem ser mistas (PIMENTEL et al., 2017). Independente das tipologias possíveis que as trilhas podem ser classificadas, há também variados tipos e objetivos das preleções das TIs nas UCs (PEDRINI E MERIANO, 2007). As preleções pedagógicas podem ocorrer também nas trilhas interpretativas marinhas (BERCHEZ et al.2007; RHORMENS et al, 2017).

\subsection{SUGESTÃo DE ROTEIRO PARA PLANEJAMENTO E REALIZAÇÃo DA AULA EXTRACLASSE}

Antes da ida para a trilha, o docente tem que apresentar aos alunos, ainda em sala, uma aula preparatória indispensável para planejamento. Essa aula preparatória deve: a) Mostrar a localização geográfica e mapa do trajeto da trilha e se situam-se numa unidade de conservação; b) Apresentar o objetivo da aula e o que será feito de uma maneira geral; c) Verificar se tem algum aluno com algum impedimento para a data prevista ou outra dificuldade que não possa dizer; d) Potencializar a importância e os benefícios da aula extraclasse; e) Ressaltar a necessidade dos alunos manterem-se unidos, calados por mais tempo, relaxados e tranquilos para ouvirem o docente e aproveitarem o ambiente natural; f) Orientar quanto ao tipo de roupa que deverão usar; g) Informar quanto a segurança e materiais que deverão levar para sua proteção; h) Conhecer as expectativas dos alunos quanto a aula extraclasse e se já conhecem a trilha; j) Acertar como será a conduta de todo o grupo durante a aula (levar saco de lixo, não retirar nada lá, falar baixo pois o grupo é intruso, não comer, olhar onde pisa, ir ao banheiro, ninguém poderá ficar sozinho, lanche ao final); j) Combinar como será o encontro e detalhes da viagem. As atividades que podem ser desenvolvidas na trilha podem se basear em numerosas obras sobre atividades lúdicas a serem realizadas em locais naturais (CORNELL, 2008). 
Ensino, Saúde e Ambiente - V12 (2), pp. 230-259, Ago. 2019

A problematização da questão socioambiental demanda que o docente faça uma boa leitura dos autores da EA crítica como Layrargues (1999), Loureiro (2006) e Torres et al. (2014). Com essa leitura não se pode ser ingênuo de apresentar aos alunos que as causas da problemática socioambiental têm sua raiz no momento contemporâneo. As causas atuais têm raízes históricas e por isso essa abordagem é fundamental de ser feita na preleção. Em qualquer lugar por onde se percorra uma TI não se pode deixar de aproveitar a ocasião para, na preleção pedagógica, problematizar a questão socioambiental que assola o planeta. A aula extraclasse não deve ser limitada apenas a um passeio prazeroso com a transmissão passiva de informação e descompromissada com a problemática socioambiental.

O quadro 3 apresenta um rol de orientações para organização de uma preleção a ser realizada em cada ponto interpretativo, numa TI em ambiente construído ou natural. Essas orientações são propostas para cada modelo com sugestões de apoio instrucional baseado em literatura didática. As orientações são baseadas nos indicadores que caracterizam o ambiente local, a questão socioambiental e a sua problematização. O ambiente local pode ser minimamente caracterizado pela apresentação de sua geobiodiversidade (flora, fauna e solo), diversidade humana, cultura local e ocupação do território. A questão socioambiental deve ser abordada de forma crítica.

Quadro 3: Roteiro Sintético para as aulas a serem ministradas nas trilhas interpretativas com proposta de orientações para as preleções a serem realizadas em ambientes construídos ou naturais. A trilha poderá ser equipada com placas interpretativas ou não, mas o preletor terá que ser um docente, monitor ou condutor capacitado previamente. Legenda: I: Dentro da sala; E: fora da sala de aula, mas dentro da escola; PP: Praça Pública; AN: Área Natural; UC: Unidade de Conservação da Natureza, RC: Roda de Conversa em Pé: P: Pôster Portátil; PR: Preleção Oral. PI: Ponto Interpretativo. *: Ocorrência 
Ensino, Saúde e Ambiente - V12 (2), pp. 230-259, Ago. 2019

\begin{tabular}{|c|c|c|c|c|c|c|}
\hline & Roteiro Sintético da Aula Extraclasse na Trilha Interpretativa (TI) & \multicolumn{5}{|c|}{ Ambiente } \\
\hline PI & Ponto Interpretativo & \multicolumn{2}{|c|}{ Interno } & \multicolumn{3}{|c|}{ Externo } \\
\hline \multirow{3}{*}{0} & \multirow{3}{*}{$\begin{array}{l}\text { Chegada ao local previamente combinado na TI. Caso haja armários } \\
\text { com chaves guardar as pranchetas com pré/pós-testes, e o material } \\
\text { didático e pessoal. Caso o docente tenha levado monitores para } \\
\text { ajudar seria interessante rever a preleção a ser ministrada. }\end{array}$} & \multirow{2}{*}{\multicolumn{2}{|c|}{ Sala }} & $\mathrm{P}$ & A & $\mathrm{U}$ \\
\hline & & & & $\mathrm{P}$ & $\mathrm{N}$ & $\mathrm{C}$ \\
\hline & & I & E & & & \\
\hline \multicolumn{7}{|c|}{ Concentração dos alunos para aplicação do pré-teste sobre a prancheta } \\
\hline \multirow{7}{*}{1} & PI Percepção dos sentidos básicos do ser humano & & & & & \\
\hline & $\begin{array}{l}1.1 \text { Visão: Colocar vendas nos alunos que perceberão como a falta da } \\
\text { visão lhes deixa desorientados e aguça outros sentidos como a audição. }\end{array}$ & * & * & * & * & * \\
\hline & 1.2. Respiração: Inspiração/Expiração: prendê-la por instantes & * & * & * & * & * \\
\hline & $\begin{array}{l}\text { 1.3. Audição (fechar os olhos para concentração): Sons naturais: } \\
\text { pássaros/grilos/sapos; sons artificiais: buzinas de trânsito ou vozerio de } \\
\text { rua (se na cidade); imitar sons agradáveis. }\end{array}$ & * & * & * & * & * \\
\hline & 1.4. Olfato: flores naturais, folha esmagada; fruta mordida; terra molhada & $*$ & * & * & * & * \\
\hline & $\begin{array}{l}\text { 1.5. Tato: pegar uma pedra, se possível, úmida; pisar, com cuidado, } \\
\text { descalço no capim/grama; tocar numa roupa ou caneta. Improvisar. }\end{array}$ & * & * & * & * & * \\
\hline & 1.6. Paladar: morder frutas; mastigar comida, chupar bala, etc. & * & * & * & * & * \\
\hline 2 & $\begin{array}{l}\text { PI sobre a história local. Relatar a conquista do território pelas oligarquias } \\
\text { que exploraram o solo brasileiro desde as capitanias hereditárias; pode ser } \\
\text { brevemente dramatizado. }\end{array}$ & $P$ & $P$ & $\begin{array}{l}\mathrm{R} \\
\mathrm{C}\end{array}$ & $\begin{array}{l}\mathrm{R} \\
\mathrm{C}\end{array}$ & $\begin{array}{l}\mathrm{R} \\
\mathrm{C}\end{array}$ \\
\hline 3 & $\begin{array}{l}\text { PI dos recursos naturais locais para reconhecer os ambientes construídos } \\
\text { e naturais - como os geológicos-solo, por exemplo. }\end{array}$ & $P$ & $\mathrm{P}$ & $\begin{array}{l}\mathrm{R} \\
\mathrm{C}\end{array}$ & $\begin{array}{l}\mathrm{R} \\
\mathrm{C}\end{array}$ & $\begin{array}{l}\mathrm{R} \\
\mathrm{C}\end{array}$ \\
\hline 4 & $\begin{array}{l}\text { PI dos recursos naturais para reconhecer a fauna/flora e sua interação por } \\
\text { meio de uma teia trófica contextual. }\end{array}$ & P & $P$ & $P$ & $P$ & $P$ \\
\hline 5 & PI sobre a cultura local. & $P$ & $P$ & $P$ & $P$ & $P$ \\
\hline 6 & $\begin{array}{l}\text { PI sobre as causas dos problemas socioambientais da região da trilha, } \\
\text { discutindo-os criticamente. }\end{array}$ & $\begin{array}{l}\mathrm{P} \\
\mathrm{R}\end{array}$ & $\begin{array}{l}\mathrm{P} \\
\mathrm{R}\end{array}$ & $\begin{array}{l}\mathrm{P} \\
\mathrm{R}\end{array}$ & $\begin{array}{l}P \\
R\end{array}$ & $\begin{array}{l}\mathrm{P} \\
\mathrm{R}\end{array}$ \\
\hline 7 & $\begin{array}{l}\text { PI sobre as consequências históricas socioambientais do Homem frente } \\
\text { às injustiças e irresponsabilidades do capitalismo selvagem. }\end{array}$ & P & $P$ & P & $P$ & $P$ \\
\hline 8 & $\begin{array}{l}\text { PI sobre o protagonismo individual e coletivo do aluno em relação ao } \\
\text { enfrentamento da problemática da questão socioambiental e aí dar } \\
\text { sugestões de enfrentamento (nível individual/coletivo). }\end{array}$ & $\begin{array}{l}\mathrm{P} \\
\mathrm{R}\end{array}$ & $\begin{array}{l}\mathrm{P} \\
\mathrm{R}\end{array}$ & $\begin{array}{l}\mathrm{P} \\
\mathrm{R}\end{array}$ & $\begin{array}{l}P \\
R\end{array}$ & $\begin{array}{l}\mathrm{P} \\
\mathrm{R}\end{array}$ \\
\hline 9 & $\begin{array}{l}\text { PI para realização da síntese conclusiva do que foi interpretado com os } \\
\text { alunos em toda trilha. }\end{array}$ & $\begin{array}{l}\mathrm{P} \\
\mathrm{R}\end{array}$ & $\mathrm{P}$ & $\mathrm{P}$ & $P$ & $\begin{array}{l}\mathrm{P} \\
\mathrm{R}\end{array}$ \\
\hline 10 & $\begin{array}{l}\text { Retorno ao ponto inicial ou a um local onde tenha condições para } \\
\text { aplicação do pós-teste. }\end{array}$ & * & * & * & * & * \\
\hline
\end{tabular}

Autor 


\section{CONCLUSÃO}

As aulas extraclasses realizadas em trilhas interpretativas através de preleções em ambientes terrestres ou aquáticos de água doce ou marinhos vem aumentando na última década. Pesquisas estimando esse quantitativo no país mostraram que há centenas de trabalhos desenvolvidos. As aulas extraclasse, abordando questões de cunho socioambiental provavelmente de docentes de Biologia e Ciências-conteúdo biologia vêm dominando os trabalhos publicados em TIs. Revisões bibliográficas recentes vêm evidenciando que o referencial teórico crítico para as práticas nas TIs alardeado por seus autores não estão se configurando como tal quando avaliadas de modo independente. Porém, o número de trabalhos avaliados tem sido muito restrito e não tem apresentado uma tipologia de análise como ora está sendo disponibilizada.

A análise realizada a partir de amostragem de trabalhos que cobriu ampla variabilidade de aulas extraclasses em trilhas interpretativas pelo país aponta deficiências e falta de efetividade das aulas tanto na formulação da preleção no aspecto humanista, quanto na problematização da questão socioambiental. É apresentada então uma proposta de classificação de efetividade das preleções das aulas nas trilhas interpretativas, tendo por base a diversidade tanto humana como da geobiológica. Valoriza a problematização críticafreiriana da questão socioambiental incluída na preleção. Cria diferentes níveis de efetividade desde a efetividade plena até a inefetiva, produzindo assim unidades de comparação entre diferentes trabalhos.

São propostos modelos de orientações para cinco contextos de ensino onde um docente pode ministrar aulas extraclasses em trilhas interpretativas. Essas sugestões tencionam possibilitar uma ideia inicial para docentes inexperientes. Apresenta modelos de aulas para nove pontos interpretativos para os cinco contextos de ensino derivados da leitura dos trabalhos arrolados na leitura crítica e reflexiva da revisão bibliográfica.

A perspectiva crítica-freiriana de educação ambiental permeia toda a problematização do presente artigo, embora não seja a única possível de alcançar sucesso frente aos enormes desafios tanto na educação da juventude como no enfrentamento das desordens socioambientais causadas pelo capitalismo selvagem que enfrentamos desde a revolução industrial. E para concluir..... 
Ensino, Saúde e Ambiente - V12 (2), pp. 230-259, Ago. 2019

Paulo Freire em sua obra Pedagogia da Autonomia quando apresenta seus cerca de 30 pressupostos pedagógicos para a prática educativa nas escolas sugeriu exercícios claramente de educação ambiental transformadora para a sala de aula (FREIRE, 2011, p. 31/32):

"Por que não aproveitar a experiência que têm os alunos de viver em áreas da cidade descuidadas pelo poder público para discutir, por exemplo, a poluição dos riachos e dos córregos e os baixos níveis de bem-estar das populações, os lixões e os riscos que oferecem à saúde das gentes?" (FREIRE, 2011, p. 31/32)

\section{AGRADECIMENTOS}

Aos colegas do CIN/CNEN especialmente a Bibliotecária Maria Emília Frade de Mello e o Dr. Luís Fernando Sayão pelo apoio incondicional de ambos para a obtenção do meu doutoramento pela Universidade Federal do Rio de Janeiro. A educadora freiriana Dra. Juliana Rezende Torres docente da UFSCar pela revisão do artigo. Ao estimado aluno da Biologia da UERJ Juan Luiz Alcântara Fernandes da Silva pela ajuda na finalização dos quadros. A minha esposa Rosana Nunes Pedrini pelo seu amor e revisão do texto.

\section{REFERÊNCIAS}

ALMEIDA, L. F. R.; BICUDO, L. R. H.; BORGES, G. L. A. Educação Ambiental em Praça Pública: Relato de Experiência com Oficinas Pedagógicas. Ciência \& Educação, v. 10, n. 1, p. 133-147, 2004.

ALVES, L. M. Trilha interpretativa da EMBRAPA ("trilha da Matinha"), Dourados/MS: Contexto para Educação Ambiental. 2013. 118 f. Dissertação (Mestrado em Ensino de Ciências), Fundação Universidade Federal de Mato Grosso do Sul, Campo Grande, 2013.

ANDRADE, W. J.; ROCHA, L. M. Planejamento, implantação e manutenção de trilhas interpretativas. São Paulo: Sociedade Educativa Gaia, 1997, 34 p.

ANGELINI, R.; FERREIRA, J.S.; ARAUJO, C.S. DO C. et al. Effect of outdoor and laboratorial Environment Science Activities on Middle Scool Students Undestanding on Conservation. Nature \& Conservation, v. 9, n. 1, p. 1-5, 2011.

ARAÚJO, B. F. Trilha Interpretativa nos biomas da Mata Atlântica e na Caatinga a partir da percepção ambiental dos estudantes do ensino médio. 2016. Dissertação (Mestrado em Ensino de Ciências e Matemática), Programa de Pós-Graduação em Ensino de Ciências e Matemática, Universidade Federal da Alagoas, Maceió, 2016. 
Ensino, Saúde e Ambiente - V12 (2), pp. 230-259, Ago. 2019

ARAÚJO, L. da S. Desenvolvimento de um aplicativo móvel de realidade aumentada para a trilha dos estudantes do Parque Nacional da Tijuca (RJ). 2019. Monografia (Licenciatura em Ciências Biológicas), Instituto de Biologia Roberto Alcântara Gomes, Universidade do Estado do Rio de Janeiro, Rio de Janeiro, 2019.

ARAÚJO, M. L. F.A Educação Ambiental Crítico-Humanizadora na formação de professores de Biologia. Recife: Ed. UFPE, 2015, 374 p.

ARAÚJO, D.; FARIAS, M. E. Trabalhando a construção de um novo conhecimento através dos sentidos em trilhas ecológicas. In: SIMPÓSIO SUL BRASILEIRO DE EDUCAÇÃO AMBIENTAL, 2., Anais..., 2003, Itajaí: Unilivre, 2003.

ARAÚJO, C. S. DO C., SIMIÃO-FERREIRA, J.; FAQUIM, R. C. P. et al. Formação Inicial de Professores em Atividade de Educação Científica: Explorando Ambientes Não formais de Educação. Pesquisa em Educação Ambiental, v. 8, n. 2, p. 97-110, 2013.

BARBOSA, A.G.P.; PERINOTTO, A.R.C. Trilha Ecológica do Cavalo-Marinho: Ecoturismo em Barra Grande. Rosa dos Ventos, v.1, n.1, p. 45-55, 2010.

BARBOSA, C.; GUIMARÃES, C.; NEVES, E. Técnicas e ferramentas participativas para Educação Ambiental. Tefé: Instituto de Desenvolvimento Mamirauá, 2019, 64 p.

BARCELloS, M. M.; MAIA, S.; MEIRELES, C.; PIMENTEL, D. de S. Elaboração da Trilha Interpretativa no Morro das Andorinhas: Uma Proposta de Educação Ambiental no Parque Estadual da Serra da Tiririca, RJ. In: USO PÚBLICO EM UNIDADES DE CONSERVAÇÃO, 1. Anais..., 2013, Niterói, v.1. p. 129-140.

BERCHEZ, F.; GHILARDI, N.; ROBIM, M. de J. et al. Projeto Trilha Subaquática Sugestão de diretrizes para a criação de modelos de Educação Ambiental para ecossistemas marinhos. OLAM-Ciência e Tecnologia, v.7, n. 2, p. 181-208, 2007.

BRAGA, R. M. R. de B.; SIQUEIRA, A. E. de; WINAGRASKI, E. Guia para a trilha adaptada do Parna Tijuca: Uma Proposta Multidisciplinar sob a Perspectiva da Educação Inclusiva. Aproximando, v. 1, n. 1, p. 1-6, 2015.

CAZOTO, J. L.; TOZONI-REIS, M. F. de C. Construção Coletiva de uma Trilha Ecológica no Cerrado: Pesquisa Participativa em Educação Ambiental. Ciência \& Educação, v. 14, n. 3, p. 575-82, 2008.

CECCON, S. Trilhas interpretativas como estratégia metodológica para o ensino médio de biologia. In: EDUCERE, Anais..., 2008, p. 12397-12408. 
Ensino, Saúde e Ambiente - V12 (2), pp. 230-259, Ago. 2019

CHAPANI, D. T.; DAIBEN, A. M. L. Educação Ambiental; ação-reflexão-ação no cotidiano de uma escola pública. In: TALAMONI, J. L. B.; SAMPAIO, A. C. (Org.) Educação Ambiental: da prática pedagógica à cidadania. São Paulo: Escrituras, 2003 (Educação para Ciência, 4), p.21-40.

COPATTI, C. E.; MACHADO, J. V. de V.; ROSS, B. O Uso de Trilhas Ecológicas Para Alunos do Ensino Médio em Cruz Alta-Rs como Instrumento de Apoio a Prática Teórica. Educação Ambiental em Ação, n. 34, p.1-10, 2010/2011.

CORNELL, J. Vivências com a natureza 2; Novas atividades para pais e educadores. São Paulo: Aquariana, 2008, 219 p.

COSTA, E. S. A. da; COSTA, I. A. S. da; OliVEIRA, K. S.; MELO, A. V. de. Trilhas interpretativas na área verde da escola como estratégia de ensino para aprendizagem de conceitos Ecológicos. Revista da SBenbio, n. 7, p. 1820-1831, 2014.

CUNHA, E. G. M. Educação Ambiental em Espaço Não Formal: Produção e Análise da Aplicação de Dois Jogos sobre Aquecimento Global no mar em Praça Pública do Município do Rio de Janeiro. 2016. 98 f. Dissertação (Mestrado em Formação Científica para Professores de Biologia), Instituto de Biofísica Carlos Chagas Filho, Universidade Federal do Rio de Janeiro, Rio de Janeiro, 2016.

CURADO, P. M.; ANGELINI, R. Avaliação de atividade de Educação Ambiental em trilha interpretativa, dois a três anos após sua realização. Acta Scientiarum - Biological Sciences, v. 28, n. 4, p. 395-401, out/Dec. 2006.

DElizoicov, D.; ANGOTTI, J. A.; PERnAMBUCO, M. M. Ensino de Ciências; fundamentos e métodos. São Paulo: Cortez, 2018, 285 p.

DIAS, G. F. Dinâmicas e Instrumentação para Educação Ambiental. São Paulo: Gaia, 2010. 215 p.

DIAS, F. V.; ZANIN, E. M. Eficiência de trilhas interpretativas no Parque Municipal Longines Malinowski, Erechim-RS. Revista Perspectiva, Erechim, v. 28, p. 29-38, 2004.

DI TUlLIO, A. A abordagem participativa na construção de uma trilha interpretativa como uma estratégia de educação ambiental em São José do Rio Pardo - SP. 2005. 183 f. Dissertação (Mestrado em Ciências da Engenharia Ambiental), Escola de Engenharia de São Carlos, Universidade de São Paulo, São Paulo, 2005. 
Ensino, Saúde e Ambiente - V12 (2), pp. 230-259, Ago. 2019

EISENLOHR, P. V.; MEYER, L.; MIRANDA, P. L.S. DE; REZENDE, V. L.; SARMENTO, V. D.; MOTA, T. J.; GARCIA; L. C.; MELO, M. M. DA R. F. Trilhas e seu papel ecológico: o que temos aprendido e quais as perspectivas para a restauração de ecossistemas? Hoehnea, v. 40, n. 3, p. 407-418, 1 tab., 2013.

EL-DEIR, S. G. Metodologias inovadoras para o empoderamento social. Recife: Editora da Universidade Federal Rural de Pernambuco, 2013, 237 p.

FIGUEIREDO, J. B. A. Educação Ambiental Dialógica; as contribuições de Paulo Freire e a cultura sertaneja nordestina. Fortaleza: Ed. UFCe, 2007, 395 p.

FONTANA, C., CORAIOLA, M., BÜNDCHEN, M. Trilha Ecológica Interpretativa e Possibilidades de Educação Ambiental no Parque Natural Municipal do Vale Rio do Peixe, Joaçaba/SC. In: CONGRESSO BRASILEIRO DE UNIDADES DE CONSERVAÇÃO, 7. Anais....17 de fevereiro de 2015.

FREIRE, P. Pedagogia do oprimido. 13 ed. Rio de Janeiro: Paz e Terra,1987.

FREIRE, P. Pedagogia da autonomia: Saberes necessários à prática educativa. 43a ed. São Paulo: Paz e Terra, 2011, 143 p.

FREIRE, P. Educação e mudança. Rio de Janeiro: Paz e Terra, 2013, 46 p.

GUIMARÃES, S. T. L. Trilhas Interpretativas e Vivências na Natureza: aspectos relacionados à percepção e interpretação da paisagem. Caderno de Geografia, v.20, n.33, p.8-19, 2010.

GUERRA, A. Proposta de Trilha Interpretativa Guiada para a Mata "Vista Chinesa" da Soeicom - Lagoa Santa/Vespasiano. In: ENCONTRO DE GEÓGRAFOS DA AMÉRICA LATINA, 10., Anais...., 20 a 26 de março de 2005, Universidade de São Paulo, p. 6652-6672.

GHILARDI-LOPES; N.P., HADEL; V.F., BERCHEZ, F. Guia para Educação Ambiental em Costões Rochosos. Porto Alegre: Artmed, 2012.

IKEMOTO, S. M. As trilhas interpretativas e sua relevância para a promoção da conservação: Trilha do Jequitibá, Parque Estadual dos Três Picos (PETP), RJ. 2008. 170 f. Dissertação (Mestrado em Ciência Ambiental), Universidade Federal Fluminense, Niterói, 2008.

LAYRARGUES, P. P. A resolução de problemas ambientais locais deve ser um tema-gerador ou a atividade-fim da educação Ambiental? In: REIGOTA, M. (Org.) Verde Cotidiano: meio ambiente em discussão. Rio de Janeiro: DP\&A, 1999. 
Ensino, Saúde e Ambiente - V12 (2), pp. 230-259, Ago. 2019

LECHNER, L. Planejamento, implantação e manejo de trilhas em unidades de conservação. Cadernos de Conservação, n.3, p. 1-125, 2006.

LIMA, F. B. de; MACHADO, M. K.; HOEFEL, J. L. de M.; FADINI, A. A. B. Caminhada Interpretativa na Natureza como Instrumento para Educação Ambiental. In: ENCONTRO DE PESQUISA EM EDUCAÇÃO AMBIENTAL: ABORDAGENS EPISTEMOLÓGICAS E METODOLÓGICAS, 2., Anais..., 27 a 30 de julho de 2003, São Carlos UFSCar, p. 1-12.

LIMA, D. C. F. de; COSTA, A. D; SILVA, D. P. de M. Trilhas Interpretativas como Instrumento da Educação Ambiental: um novo olhar sobre o ambiente. In: CONGRESSO NACIONAL DE EDUCAÇÃO, 2., Anais..., 14-17 de outubro de 2015, Campina Grande, 12 p.

LOUREIRO, C. F. B. Problematizando conceitos: contribuindo a práxis em educação ambiental. In: LOUREIRO, C. F. B.; LAYRARGUES, P. P.; CASTRO, R. S. (Org.) Pensamento complexo, dialética e educação ambiental. São Paulo: Cortez, 2006, p. 104161.

LOUREIRO, C. F. B.; TORRES, J. R. Educação Ambiental, dialogando com Paulo Freire. São Paulo: Cortez, 2014. 184 p.

MACIEL, J. L.; WACHHOLZ, C. B.; ALMINHANA, C. O.; BITAR, P. G.; MUHLE, R. P. Metodologias duma Educação Ambiental Inclusiva. Revista Virtual EGP, v.1, n. 1, p. 1-11, 2010.

MARTINS, J. de F. de C.; TEIXEIRA, E. C.; SCHERER, A. L.; TEIXEIRA, E. C.; SAUL, P. F. de A. Trilha integração: integrando estudantes, visitantes e ambientes no Campus da Unisinos, RS. Revista Biodiversidade Pampeana, v. 5, n. 1, p.16-19, 2007.

MATAREZI, J. Trilha da Vida: Redescobrindo a natureza com os sentidos. Revista Eletrônica do Mestrado em Educação Ambiental, p. M.1-M.19. 2000/2001.

MATAREZI, J.; BONILHA, L. E. C. Educação Ambiental Comunitária e a conservação do litoral brasileiro: a experiência do laboratório de Educação Ambiental em áreas costeiras Centro de Ciências Tecnológicas da Terra e do Mar - CTTMAR/UNIVALI. Notas Técnicas FACIMAR, n. 4, p. 103-120, 2000.

MEC. Parâmetros Curriculares Nacionais; Temas Transversais. Brasília: MEC, 1998, $436 \mathrm{p}$. 
Ensino, Saúde e Ambiente - V12 (2), pp. 230-259, Ago. 2019

MEIRELES, C.; RIBEIRO, F. D. V.; ANDRADE, A. D.; FERREIRA, Y. D. S.; CREED, J. Implantação da primeira trilha interpretativa terrestre e subaquática em Área de Proteção Ambiental na Ilha Grande (Angra dos Reis, RJ). In: CONGRESSO NACIONAL DE PLANEJAMENTO E MANEJO DE TRILHAS, 2., Anais..., 2013, p. 863-881.

MENDONÇA, R.; NEIMAN, Z. À sombra das árvores; transdisciplinaridade e educação ambiental em atividades extraclasse. São Paulo: Chronos, 2003, 123 p.

MION, R. A.; SAITO, C. H. Investigação-Ação: Mudando o Trabalho de Formar Professores. Ponta Grossa: Gráfica Planeta, 2001. 148 p.

MORITZ, T.; GURGEL, T. de S.; COSTA, S. P. Trilhas Interpretativas Como Meio de Conscientização e Sensibilização: um estudo com participantes das trilhas da unidade de conservação Parque Estadual das Dunas de Natal-RN. Interface, v.11, n.1, p. 130-150, 2014.

MÜLLER, L.; TORRES, L. R A investigação de temas geradores para a inserção da dimensão ambiental crítico transformadora na educação escolar. In: ENCONTRO DE PESQUISA EM EDUCAÇÃO AMBIENTAL, 8., 18-22 de julho de 2015, Anais..., Rio de Janeiro, Universidade Federal do Estado do Rio de Janeiro/Universidade Federal Rural do Rio de Janeiro/ Universidade Federal do Rio de Janeiro.

PASSERI, M. G. Uso de trilhas ecológicas no Ensino de Ciências: uma análise das abordagens de Educação Ambiental em artigos científicos. 2016. 98 f. Trabalho de Conclusão de Curso (Especialização em Ensino de Ciências), Instituto de Biologia Roberto Alcântara Gomes, Universidade do Estado do Rio de Janeiro, Rio de Janeiro, 2016.

PEDRINI, A. G. Avaliação da Educação Ambiental no Ecoturismo (com Trilhas): Uma Proposta Metodológica de Qualidade Conceitual. OLAM - Ciência e Tecnologia, v. 7, n. 2, p. 83-106, 2006.

PEDRINI, A. G. (Org.) Macroalgas (Ocrófitas Multicelulares) Marinhas do Brasil. Rio de Janeiro: Technical Books, 2013a, 173 p.

PEDRINI, A. G. Trilhas Marinhas no Brasil; uma Síntese para a Educação Ambiental, In: CONGRESSO NACIONAL DE PLANEJAMENTO E MANEJO DE TRILHAS, 2., Anais.... 2013b, p.1272-1279, Universidade do Estado do Rio de Janeiro, Rio de Janeiro (RJ), Brasil. (CD-ROM).

PEDRINI, A. G.; MERIANO, D.N. Avaliação da qualidade do ecoturismo terrestre no Brasil: estudo de caso com uma empresa atuante em trilhas, RJ. In: CONGRESSO NACIONAL DE ECOTURISMO, 6., Anais..., 8-11 de novembro de 2007, Itatiaia, RJ, Brasil. 
Ensino, Saúde e Ambiente - V12 (2), pp. 230-259, Ago. 2019

PEDRINI, A. G.; LIMA, L.; VIANA, T.; BROTTO, D. S. Percepção ambiental pública sobre atitudes e responsabilidades frente às mudanças climáticas globais por frequentadores de uma praça urbana na cidade do Rio de Janeiro (RJ, Brasil) e o papel das fontes de informação. In: ENCONTRO NACIONAL DE PROGRAMAS DE PÓSGRADUAÇÃO E PESQUISA EM AMBIENTE E SOCIEDADE (ENAMPPAS) ENAMPPAS, 7., Anais..., 17-20 de maio de 2015, Brasília (DF), Universidade Nacional de Brasília. Pendrive 1.

PEDRINI, A. G.; MESSAS, T.; PEREIRA, E. da F. et al. Educação ambiental pelo ecoturismo numa trilha marinha no Parque Estadual da Ilha Anchieta, Ubatuba, São Paulo, Brasil. Revista Brasileira de Ecoturismo, v.3, n.3, p.428-459, 2010.

PEDRINI, A. G.; DOMINGOS, P.; MARINHO, M. M.; GUARINO, G. I. P. Avaliação da adequação do Guia Didático de Algas Verdes, Pardas e Vermelhas Marinhas e Estuarinas do Saco de Dois Rios, Parque Estadual da Ilha Grande, Rio de Janeiro, Brasil. Resultados Preliminares. In: CONGRESSO BRASILEIRO DE FICOLOGIA, 17., Anais... 2018, Universidade Federal do Rio Grande do Norte, Natal.

PEDRINI, A. DE G; KREMER, L; BROTTO, D.S.; SILVA, V.R.F. DA. Emblematic Projects of Marine and Coastal Environmental Education in Brazil. In: GHILARDI-LOPES, N.P.; BERCHEZ, F. (Eds.) Marine and Coastal Environmental Education. Springer, Cham. 2019, p. 87-101.

PIMENTEL, D. de S.; BARCELLOS, M. M.; MEIRELES, C. P., et al. Trilhas Interpretativas como estratégia de Educação Ambiental em Unidades de Conservação. In: SANTORI, R. T., SAnTOS, M.G., SANTOS, M.C.F. (Org.) Da Célula ao Ambiente; propostas para o ensino de Ciências e Biologia. Niterói: Faculdade de Formação de Professores - FFP/UERJ, 2017, p. 179-203.

PIMENTEL, D. de S; PEDRINI, A. DE G; KAWABE, L. DE A; ROBIM, M. DE J.; BERCHEZ, F.; MEIRELES, C.P. Opportunities and challenges to implement Environmental Education in Brazilian Coastal and Marine Protected Areas. In: GHILARDI-LOPES, N. P.; BERCHEZ, F. (Eds.) Marine and Coastal Environmental Education. Springer, Cham, 2019, p. 103-117.

QUINTAS, J. S. Educação no processo de gestão ambiental pública: a construção do ato pedagógico. In: LOUREIRO, C. F.; LAYRARGUES, P. P.; CASTRO, R. S. de (Org.) Repensar a educação ambiental. São Paulo: Cortez, 2009, p. 33-80. 
Ensino, Saúde e Ambiente - V12 (2), pp. 230-259, Ago. 2019

RHORMENS, M. S.; PEDRINI, A. G.; GHILARDI-LOPES, N. Implementation Feasibility of a marine ecotourism product on the reef environments of the Marine Protected Area of Tinharé and Boipeba Islands, (Cairu, Bahia, Brazil). Ocean and Coastal Management, v. 139, p. 1-11, 2017.

ROCHA, M. B.; PIN, J. R. de O.; GÓES, Y. C. B.; RODRIGUES, L. A. Análise de contribuição de uma trilha ecológica para a sensibilização ambiental de estudantes da educação básica. In: ENCONTRO DE PESQUISA EM EDUCAÇÃO AMBIENTAL, 4., Anais..., 13-16 de agosto de 2017a, Juiz de Fora, UFJF, p. 1-10.

ROCHA, O. dos S; SILVA, M. A.; LOPES, M. O Método de Paulo Freire na Educação Ambiental com o uso de aplicativo de informática para dispositivos móveis. AmbientalMENTEsustentable, v. 1, n. 23-24, p. 372-385, $2017 \mathrm{~b}$.

SAITO, C. H.” Cocô na praia, não" - Educação Ambiental, ensino de ciências e lutas populares. Ambiente e Educação, Rio Grande, v. 4, p. 45-57, 1999.

SAITO, C. H. Popularizando o ProBIO-Educação Ambiental na Praça e na Escola. Revista Brasileira de Educação Ambiental, Rio Grande, v.7, n. 2, p. 83-95, 2012.

SAITO, C. H.; FIGUEIREDO, J.; VARGAS, I. A. Educação Ambiental Freiriana no contexto de formação de educadores ambientais. In: PEDRINI, A. de G., SAITO, C. H. (Org.) Paradigmas Metodológicos em Educação Ambiental. Petrópolis: Vozes, 2014, p. 71-81.

SANTOS, C. G. Educação Ambiental e ecologismo nas trilhas da caminhada ecológica:

Estudo de Caso. 2007. 123 f. Dissertação (Mestrado em Ciência Ambiental), Programa de Pós-Graduação em Ciência Ambiental, Instituto de Geociências, Universidade Federal Fluminense, Niterói, 2007.

SANTOS, F. C. dos; SILVA, F. A. R. As trilhas ecológicas e o ensino de ciências: análises dos últimos anais dos encontros de Ensino de Ciências, Biologia e Educação Ambiental no Brasil. In: ENCONTRO NACIONAL DE PESQUISA EM EDUCAÇÃO EM CIÊNCIAS (ENPEC), 10., Anais..., 24-27 de novembro de 2011, Águas de Lindóia (SP).

SANTOS, R. L. F. dos; ALMEIDA, R. de C. de. Educação Ambiental e Trilhas Ecológicas: o caminhar para um Futuro Consciente e Sustentável. Revista Científica do Unisalesiano, n.4, p. 265-276, 2011.

SANTOS, D. A. dos, PIMENTEL, D. M.; MENDES, R. R. L. Produção e Avaliação de Guias Didáticos sobre ecologia e biodiversidade na Licenciatura em Ciências Biológicas da FFP Uerj, In: SANTORI, R. T.; SANTOS, M. G; SANTOS, M.C. F. dos. (Org.). Da Célula ao 
Ensino, Saúde e Ambiente - V12 (2), pp. 230-259, Ago. 2019

Ambiente; propostas para o ensino de Ciências e Biologia. Niterói: Faculdade de Formação de Professores - FFP/UERJ, 2017, p. 31-46.

SENICIATO, T.; CAVASSAN, O. Aulas de campo em ambientes naturais e aprendizagem em ciências - um estudo com alunos do ensino fundamental. Ciência \& Educação, v.10, n.1, p.133-147, 2004.

SIQUEIRA, A. E. (Org.). Guia de campo do Parque Nacional da Tijuca. Rio de Janeiro: Universidade do Estado do Rio de Janeiro, 2013. (1 CD ROM)

SOUSA, D. M.; CREMER, M. J. A trilha ambiental interpretativa em uma unidade de conservação como ferramenta de sensibilização de escolar e uma abordagem quantitativa na rede municipal de ensino de Joinville, Santa Catarina. Pesquisa em Educação Ambiental, v. 11, n. 1, p. 94-109, 2016.

STEINERT, M. E. P.; HARDOIM, E. L. Leigos ou excluídos? A criação de um aplicativo educacional e seu uso via ensino híbrido em uma escola pública. Revista Sustinere, v. 5, n. 1, p. $90-113,2017$.

TABANEZ, M. F.; PÁDUA, S.M.; SOUZA, M.G.; CARDOSO, M.M.; GARRIDO, L.G. Avaliação de Trilhas Interpretativas para a Educação Ambiental. In: PÁDUA, S.M.; TABANEZ, M. (Org.) Educação Ambiental: caminhos trilhados no Brasil. Brasília: IPÊ, 1997, p. 89-102.

TElleS, M. Q.; ROCHA, M. B.; PEDROSO, M. L.; MACHADO, S. M. C. Vivências Integradas com o Meio Ambiente. Práticas de Educação Ambiental para Escolas, Parques, Praças e Zoológicos. São Paulo: Sá Editora, 2002. 145 p.

TILDEN, F. Interpreting our Heritage. Chapell Hill: The University of Chapel Hill: North Carolina Press, 1977.

TORRES, J. R. Educação Ambiental crítica-transformadora no contexto escolar: um exemplar. In: DICKMANN, I; BATTESTIN, C. (Org.) Educação Ambiental na América Latina. Chapecó: Plataforma Acadêmica, 2018, p. 155-184.

TORRES, J. R.; DELIZOICOV, D. Os fundamentos da concepção educacional de Paulo Freire na pesquisa em Educação Ambiental no contexto formal: 12 anos de ENPEC. In: ENCONTRO NACIONAL DE PESQUISA EM EDUCAÇÃO EM CIÊNCIAS, Anais...Florianópolis, 2009 (CD-ROM). 
Ensino, Saúde e Ambiente - V12 (2), pp. 230-259, Ago. 2019

TORRES, J. R.; FERRARI, N.; MAESTRELli, S. R. P. Educação Ambiental críticatransformadora no contexto escolar: teoria e prática freiriana. In: LOUREIRO, C. F. B.; TORRES, J. R. (Org.) Educação Ambiental, dialogando com Paulo Freire. São Paulo: Cortez, 2014, p. 13-80.

TORRES, J. R.; MAESTRELLI, S. R. P. Atributos da educação ambiental escolar no contexto educacional brasileiro: do movimento ambientalista internacional ao nacional. Revista Eletrônica do Mestrado em Educação Ambiental, v. 28. p. 115-132, 2012a.

TORRES, J. R.; MAESTRELLI, S. R. P. Apropriações da concepção educacional de Paulo Freire na Educação Ambiental: um olhar crítico. Revista Contemporânea de Educação, v. 7, n. 14, p. 309-334, 2012 b.

TOZONI-REIS, M. F. de C. Temas ambientais como "temas geradores": contribuições para uma metodologia educativa ambiental crítica, transformadora e emancipatória. Educar em Revista, n. 27, p. 93-110, 2006.

TOZONI-REIS, M. F. de C. (Org.). A Pesquisa-Ação-Participativa em educação ambiental; reflexões teóricas. São Paulo: Annablume, 2007, 166 p.

VASCONCELLOS, J. M. O. Educação e Interpretação Ambiental em Unidades de Conservação. Cadernos de Conservação, n. 4, p. 1-86, 2006.

ZAÚ, P. N. S. Proposta de implementação de Trilha interpretativa na Praia do Forno (Arraial do Cabo/RJ) como ferramenta de Educação Ambiental para Unidades de Conservação Marinhas. 2018. 81f. Monografia. (Bacharel em Oceanografia), Faculdade de Oceanografia, Universidade do Estado do Rio de Janeiro, Rio de Janeiro. 2018.

\section{AUTOR 1.}

Graduado em Ciências Biológicas. Mestrado em Ciências Biológicas e Doutorado em Ciência da Informação, ambos, pela Universidade Federal do Rio de Janeiro. Membro do Grupo de Trabalho de Educação Ambiental da Rede Rebentos. Facilitador da Rede de Educação Ambiental Costeira e Marinha (REACOMar) filiada à Rede Brasileira de Educação Ambiental (REBEA). Estágio na Universidade de Paris VI e Estação de Biologia Marinha de Roscoff (França) e Museu Britânico de História Natural (Inglaterra). Professor Associado no Departamento de Biologia Vegetal do Instituto de Biologia Roberto Alcântara Gomes da Universidade do Estado do Rio de Janeiro. Docente Credenciado no Mestrado de Formação em Ciências para Professores da Universidade Federal do Rio de Janeiro. 